\title{
South China Sea Isopycnal-Surface Circulation
}

\author{
Peter C. Chu \\ Department of Oceanography, Naval Postgraduate School, Monterey, California \\ RONGFENG LI \\ LASG, Institute of Atmospheric Physics, Chinese Academy of Sciences, Beijing, China
}

(Manuscript received 2 June 1999, in final form 1 December 1999)

\section{ABSTRACT}

\begin{abstract}
This paper investigates the seasonal variabilities of the South China Sea isopycnal-surface circulations and of the Kuroshio intrusion through the Luzon Strait using the U.S. Navy's climatological temperature and salinity dataset (public domain) with $12^{\circ} \times 12^{\circ}$ resolution by the P-vector method. The representative pattern is a persistent basin-scale cyclonic circulation away from the surface, and a seasonally varying circulation with a weak anticylonic gyre in the summer and a strong cyclonic gyre in the winter near the surface. This pattern is consistent with a classical view of mean cyclonic circulation in large stratified lakes and semienclosed marginal seas by Emery and Csanady and with a recent numerical simulation using the navy's Layered Ocean Model by Metzger and Hurlburt. The computed monthly volume transport through the Luzon Strait is negative (inflow) all year round with a minimum value of $-13.7 \mathrm{~Sv}$ in February (strongest intrusion) and a maximum value of $-1.4 \mathrm{~Sv}$ in September (weakest intrusion). The annual mean transport is $-6.5 \mathrm{~Sv}$ (intrusion).
\end{abstract}

\section{Introduction}

South China Sea (SCS), the largest marginal sea in the West Pacific Ocean, is separated from adjacent oceans by a chain of islands. It contains a broad shallow shelf on the south, extending along the VietnameseChinese coast to the Taiwan Strait on the north, a deep sea basin in the center, and a dangerous ground near Nansha with numerous reef islands over the southeast (Fig. 1). It has a bottom topography that makes it a unique semienclosed ocean basin overlaid by a pronounced monsoon surface wind. Extensive continental shelves (less than $100 \mathrm{~m}$ deep) are found on the western and southern parts, while steep slopes with almost no shelves are found in the eastern part of SCS. The deepest water is confined to a bowel-type trench and the maximum depth is approximately $4700 \mathrm{~m}$. The SCS joins the Pacific Ocean through the Luzon Strait between Taiwan and the Philippines. The combination of geometry, connectivity with the Pacific Ocean, and strongly variable atmospheric forcing contributes to the complex dynamics of the flow in that region (Metzger and Hurlburt 1996).

The Kuroshio, originating from the North Equatorial

Corresponding author address: Dr. Peter Chu, Department of Oceanography, Naval Postgraduate School, Monterey, CA 93943. E-mail: chu@nps.navy.mil
Current, flows northward as a western boundary current east of Luzon and Taiwan (Nitani 1970). The Luzon Strait is the principal passage through which the Pacific water enters the SCS; therefore, the mass transport through the Luzon Strait is critical in determining the characteristics of SCS waters (Shaw 1991). For example, Hu et al. (1992) believed this flow to contribute to currents in the Taiwan Strait; however, Li et al. (1996) showed that this flow did not contribute to currents in the Taiwan Strait using a numerical model. The volume transport through the Luzon Strait is uncertain. Different authors reported values ranging from 8-10 Sv by Huang et al. (1994) to $3-\mathrm{Sv}\left(1 \mathrm{~Sv} \equiv 10^{6} \mathrm{~m}^{3} \mathrm{~s}^{-1}\right)$ outflow in summer and 3-Sv inflow in winter by Wyrtki (1961). Metzger and Hurlburt (1996) estimated that the mean Kuroshio intrusion through the Luzon Strait is around 2.4-4.4 Sv (higher resolution with lower transport values) using the U.S. Navy's Layered Ocean Model (NLOM) forced by wind stress climatology with various resolution.

The seasonally reversing monsoon winds are also play an important role in determining the upper-ocean circulation (Shaw and Chao 1994). From April to August, the weaker southwesterly summer monsoon winds result in a wind stress of over $0.1 \mathrm{~N} \mathrm{~m}^{-2}$, which drives a northward coastal jet off Vietnam and anticyclonic SCS basin-scale circulation. From November to March, the stronger northeasterly winter monsoon winds corresponds to a maximum wind stress of nearly $0.3 \mathrm{~N} \mathrm{~m}^{-2}$ 


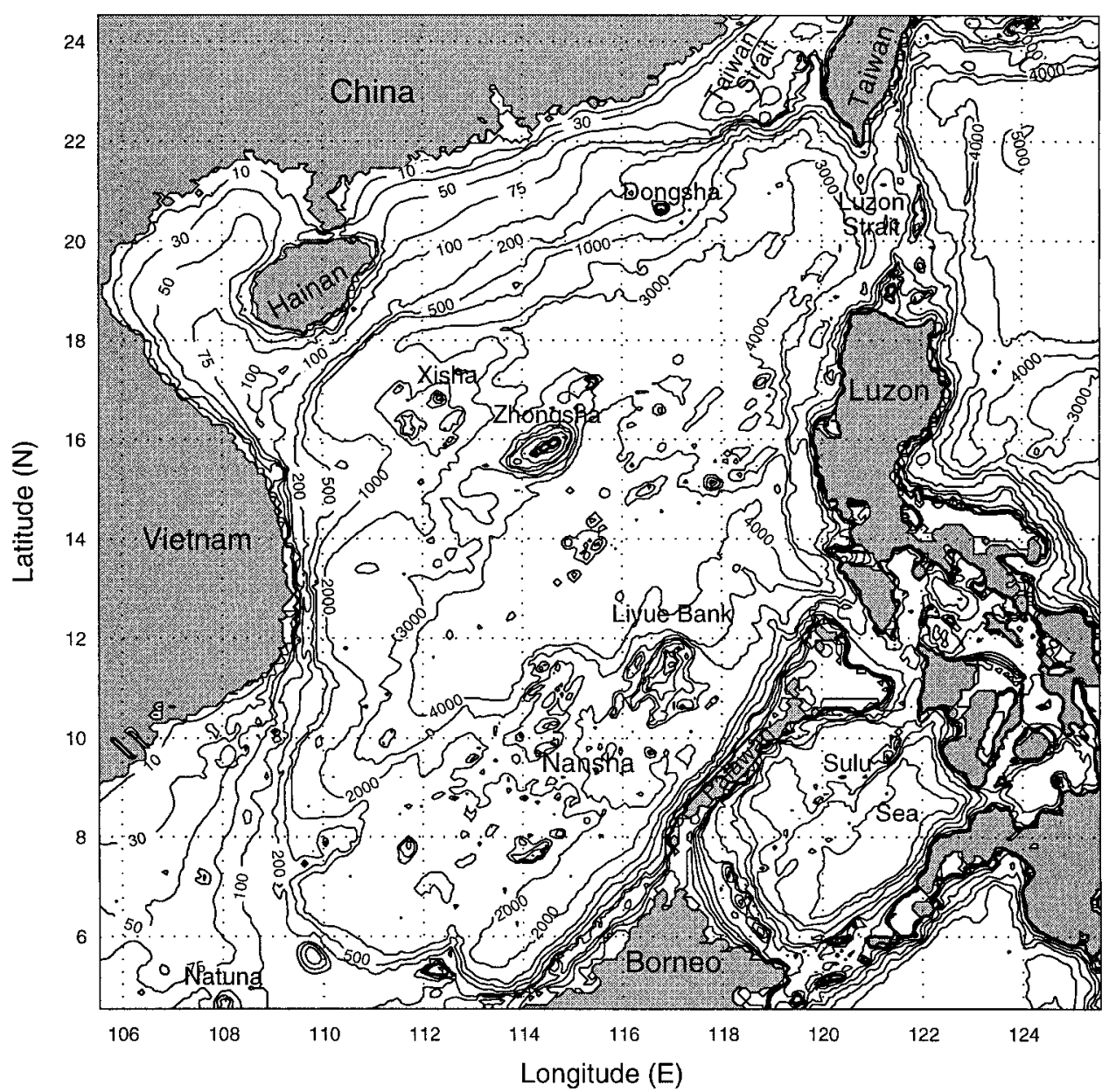

FIG. 1. Geography and isobaths showing the bottom topography of the South China Sea.

causing a southward coastal jet and cyclonic SCS basinscale circulation. Such a seasonal variability of the surface circulation was simulated by several numerical models (e.g., Chu et al. 1994, 1996, 1998c, 1999; Chao et al. 1996). However, Metzger and Hurlburt (1996) pointed out that the surface currents observed by Wyrtki (1961) are subject to Ekman drift in this highly variable wind regime.

Seasonal occurrence of SCS eddies have been reported by several authors. Dale (1956) and Uda and Nakao (1972) reported a cold eddy off the central Vietnam coast in summer. Nitani (1970) found a cold eddy located northwest of Luzon in summer. Reports from the South China Sea Institute of Oceanology (1985) indicate that a warm-core eddy appears in summer and winter in the central SCS, but in summer, it is closer to Vietnam at the surface. Recently, a cold-core eddy was detected in the central SCS during 29 December 19935 January 1994, from the analysis of TOPEX/Poseidon data (Soong et al. 1995). Chu et al. (1997b) and Chu and Chang (1997) identified the existence of a central SCS surface warm-core eddy in mid-May from a his- torical dataset: the U.S. Navy's Master Observational Oceanographic Data Set (MOODS). From the composite analysis on the U.S. National Centers for Environmental Prediction (NCEP) monthly sea surface temperature (SST) fields (1982-94), Chu et al. (1997a) found that during the spring-to-summer monsoon transition (March-May) a warm anomaly (greater than $1.8^{\circ} \mathrm{C}$ ) is formed in the central SCS at $112^{\circ}-119^{\circ} 30^{\prime} \mathrm{E}, 15^{\circ}-$ $19^{\circ} 30^{\prime} \mathrm{N}$. Emery and Csanady (1973) reported that many large stratified lakes and semienclosed marginal seas and estuaries exhibit a persistent cyclonic circulation. Integrating NLOM to the statistically equilibrium state, Metzger and Hurlburt (1996) simulated a persistent cyclonic circulation in the SCS upper layer with an approximate thickness of $250 \mathrm{~m}$.

Questions arise: is Emery and Csanady's (1973) viewpoint or Metzger and Hurlburt's (1996) cyclonic circulation pattern representative for the SCS circulations below the mixed layer? What is the seasonal variability of the Kuroshio intrusion through the Luzon Strait? The traditional geostrophic calculation cannot lead to the answers since only the baroclinic part is obtained. Thus, 
we use the P-vector method (two-step $\beta$-spiral method) to invert the absolute geostrophic circulations (both barotropic and baroclinic parts) on the isopycnal surfaces from the navy's public domain Global Digital Environmental Model (GDEM) climatological monthly mean temperature and salinity data set with $12^{\circ} \times 1 / 2^{\circ}$ resolution (Teague et al. 1990).

The outline of this paper is as follows. Section 2 depicts the navy's GDEM dataset. Section 3 describes the inversion of the absolute geostrophic velocity on the isopycnal surfaces. Section 4 depicts the thermohaline features at the intermediate depth using the GDEM data. Section 5 describes the computation in the isopycnal coordinate system. Section 6 depicts the monthly mean inverted velocity fields. Section 7 discusses the seasonal variability of the Kuroshio intrusion through the Luzon Strait. Section 8 presents the conclusions.

\section{The navy's GDEM dataset}

GDEM is the navy's global climatological monthly mean temperature and salinity data set with a four-dimensional (latitude, longitude, depth, and month) display. Data for building the current version of GDEM climatology for the SCS were obtained from MOODS, which has 144135 temperature and 13768 salinity profiles for 1930-97. The main limitation of the MOODS data is its irregular distribution in time and space (Chu et al. 1997c). Certain periods and areas are over sampled while others lack enough observations to gain any meaningful insights. Vertical resolution and data quality are also highly variable depending much on instrument type and sampling expertise. The monthly distributions of the total SCS temperature (Fig. 2a) and salinity (Fig. 2b) stations show that the number of temperature stations is 10 times more than the number of salinity stations. The monthly distributions of the SCS temperature (Fig. 2c) and salinity (Fig. 2d) stations with the profile deeper than 400-m depth are approximately one third of the total stations. Although the number of observations below $400 \mathrm{~m}$ is much smaller, the monthly station distributions (Figs. 2c,d) still show sufficient data to build up the GDEM climatology.

Yearly temperature (Fig. 3a) and salinity (Fig. 3b) profile numbers show temporally uneven distribution with almost no observations in the whole SCS in certain years (e.g., 1944 for temperature, and 1944-46, 195254, 1993-95 for salinity) and many observations in other years (e.g., more than 12000 temperature profiles in 1966 and 1968, and more than 1100 salinity profiles in 1981). Spatial and temporal irregularities along with the lack of data in certain regions must be carefully weighted in order to avoid statistically induced variability.

The basic design concept of GDEM is the determination of a set of analytical curves that represent the mean vertical distributions of temperature and salinity for grid cells $\left(0.5^{\circ} \times 0.5^{\circ}\right)$ through the averaging of the coefficients for the curves found for individual profiles
(Teague et al. 1990). Different families of representative curves have been chosen for shallow, middepth, and deep-depth ranges, with each chosen so that the number of parameters required to yield a smooth, mean profile over the range was minimized. As pointed by Teague et al. (1990), large-scale oceanographic features are generally found to be similarly represented in both GDEM and the National Oceanographic and Atmospheric Administration Climatological Atlas of the World Ocean temperature and salinity. GDEM appears to render better representations of seasonal variability and regions of high current shear because of a different smoothing method and a finer-grid spacing. GDEM data contains the monthly mean temperature and salinity $(T, S)$ and annual mean temperature and salinity $(\bar{T}, \bar{S})$ fields. Interested readers are referred to Teague et al. (1990) for more informations.

\section{Determination of absolute geostrophic flow}

Chu et al. (1998c) showed from a numerical study that the oceanographic conditions of SCS is closely related to monsoon, and especially the wind stress largely affect the near-surface (30-m depth) seasonal circulation. However, the wind effect weakens with the depth. The thermohaline circulation becomes important in the sub-surface layer. In this study, we use the GDEM data to invert the absolute geostrophic velocity on isopycnal surfaces. The inverse method proposed in this section is the two-step $\beta$-spiral method: (a) determining the direction of the velocity, and then (b) determining the magnitude of the velocity.

\section{a. Geostrophic flow on isopycnal coordinates}

As pointed out by Stommel and Schott (1977) and Wunsch (1978), in determining large-scale circulation from hydrographic data, we can be reasonably confident on the assumptions of geostrophic balance, mass conservation, and no major cross-isopycnal mixing (except water masses are in contact with the atmosphere). The potential density $(\rho)$ of each fluid element would be conserved.

The isopycnal coordinate system $(x, y, \rho)$ is used with $x$ axis in the zonal direction, $y$ axis in the longitudinal direction, $\rho$ axis in vertical. The geostrophic balanced motion on an isopycnal surface, $\rho$, with a pressure, $p$, is given by (Bleck and Smith 1990)

$$
f u=-\frac{\partial M}{\partial y}, \quad f v=\frac{\partial M}{\partial x},
$$

where $u, v$ are velocity components in $x$ and $y$ axes, $M$ $=p / \rho+g z$, is the Montgomery potential. The hydrostatic balance is written by

$$
\frac{p}{\rho^{2}}+\frac{\partial M}{\partial \rho}=0 .
$$


(a)
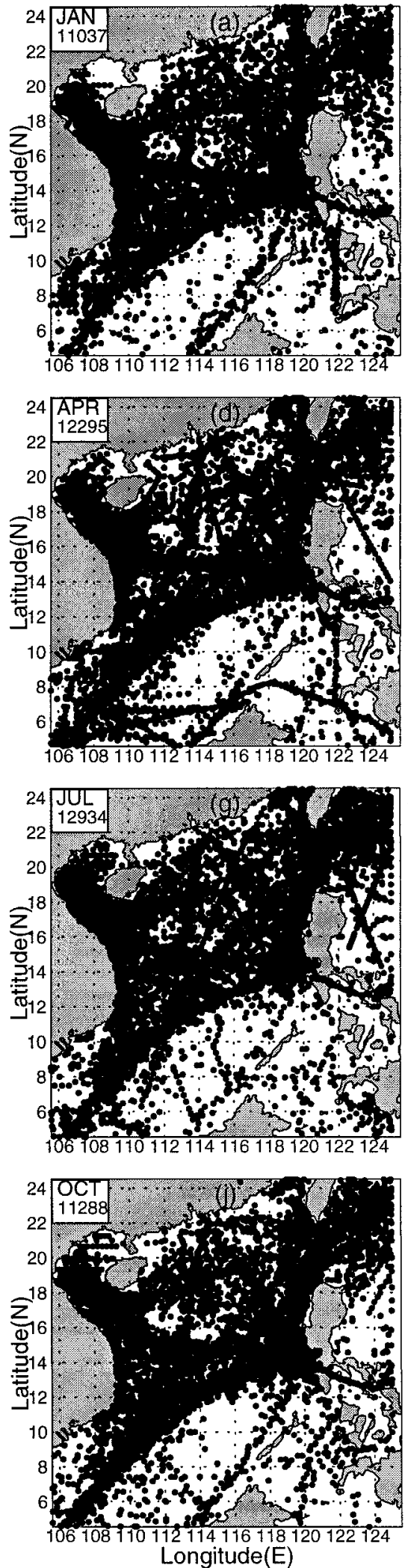
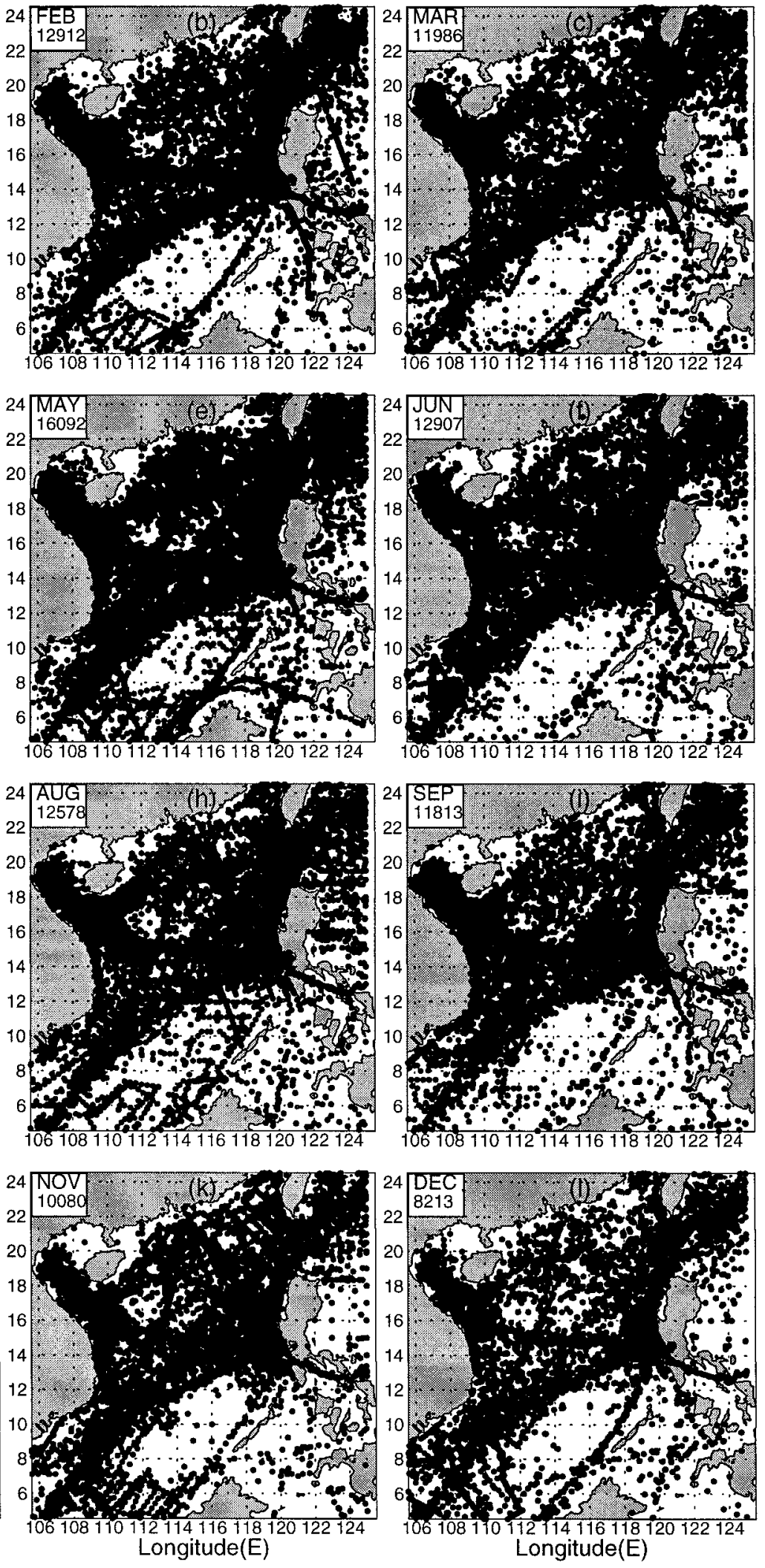

FIG. 2. Spatial distributions of MOODS stations during 1930-97: (a) total temperature stations, (b) total salinity stations, (c) temperature stations with depths deeper than $400 \mathrm{~m}$, and (d) salinity stations with depths deeper than $400 \mathrm{~m}$. 
(b)
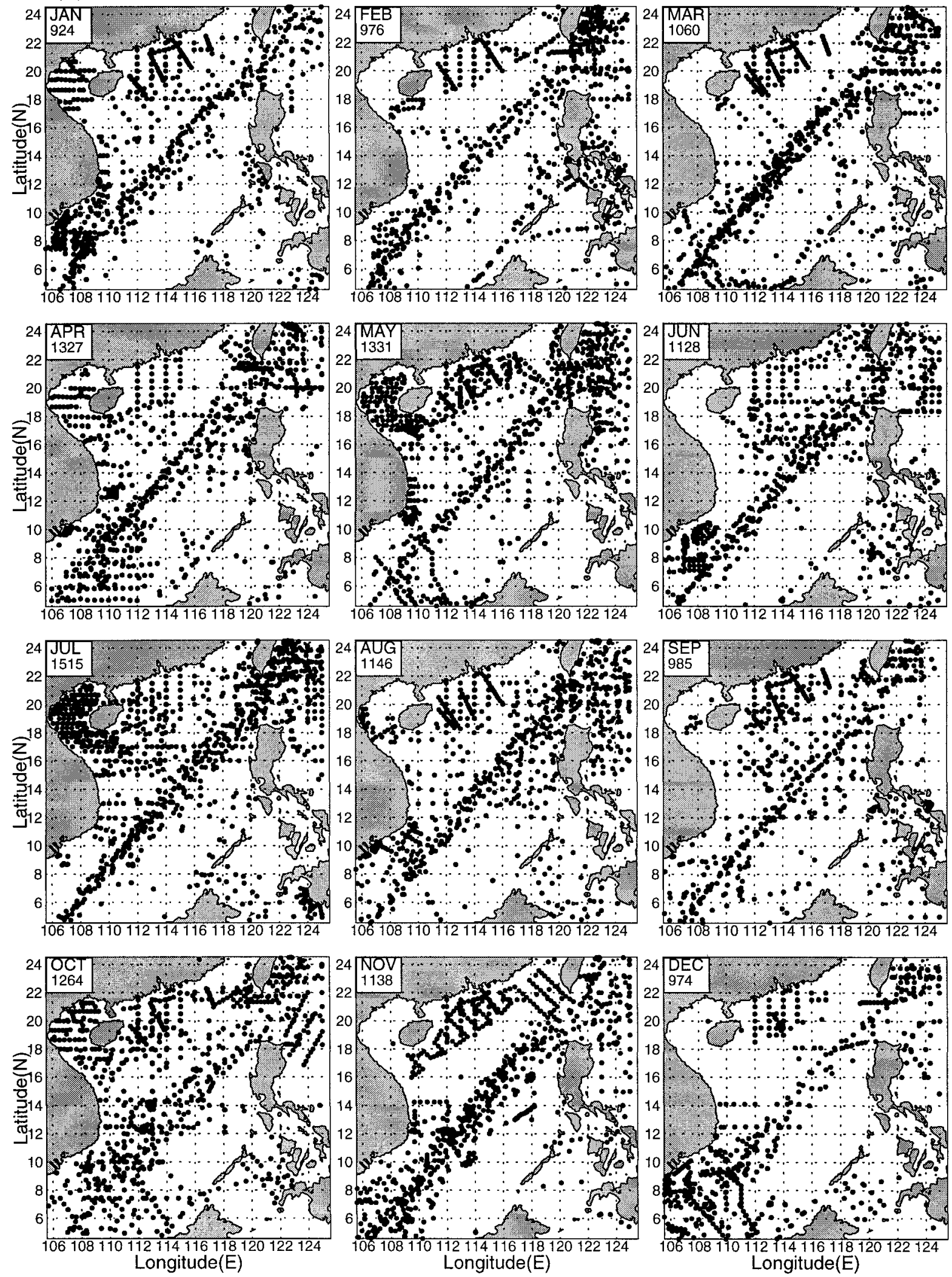

FIG. 2. (Continued) 
(c)
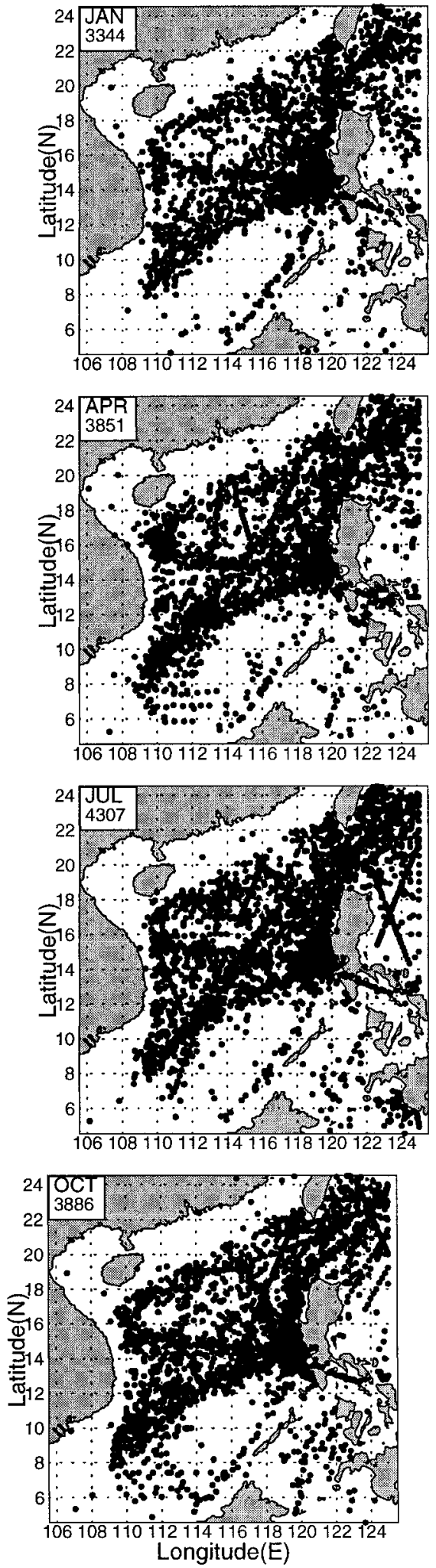
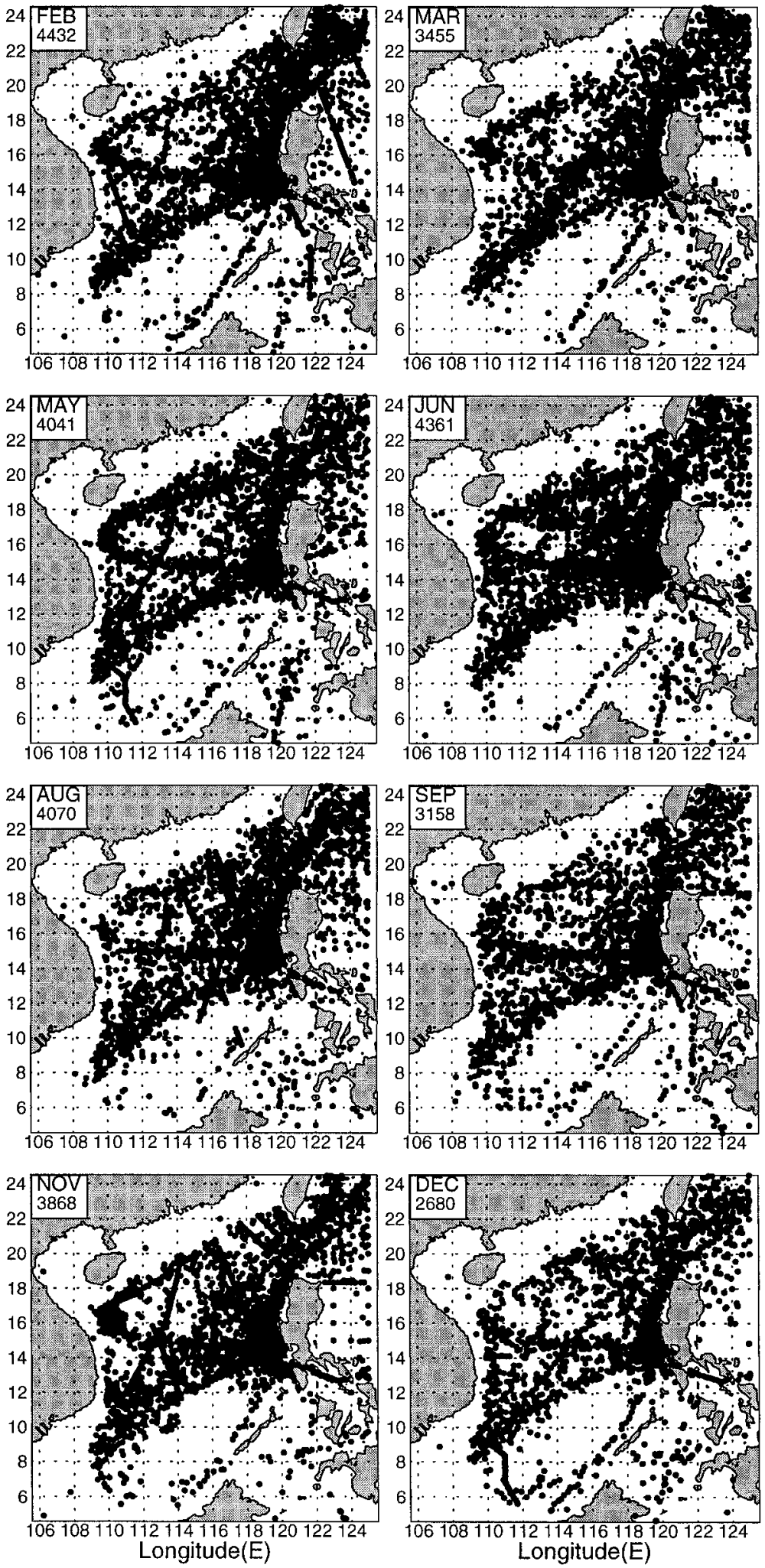

FIG. 2. (Continued) 
(d)
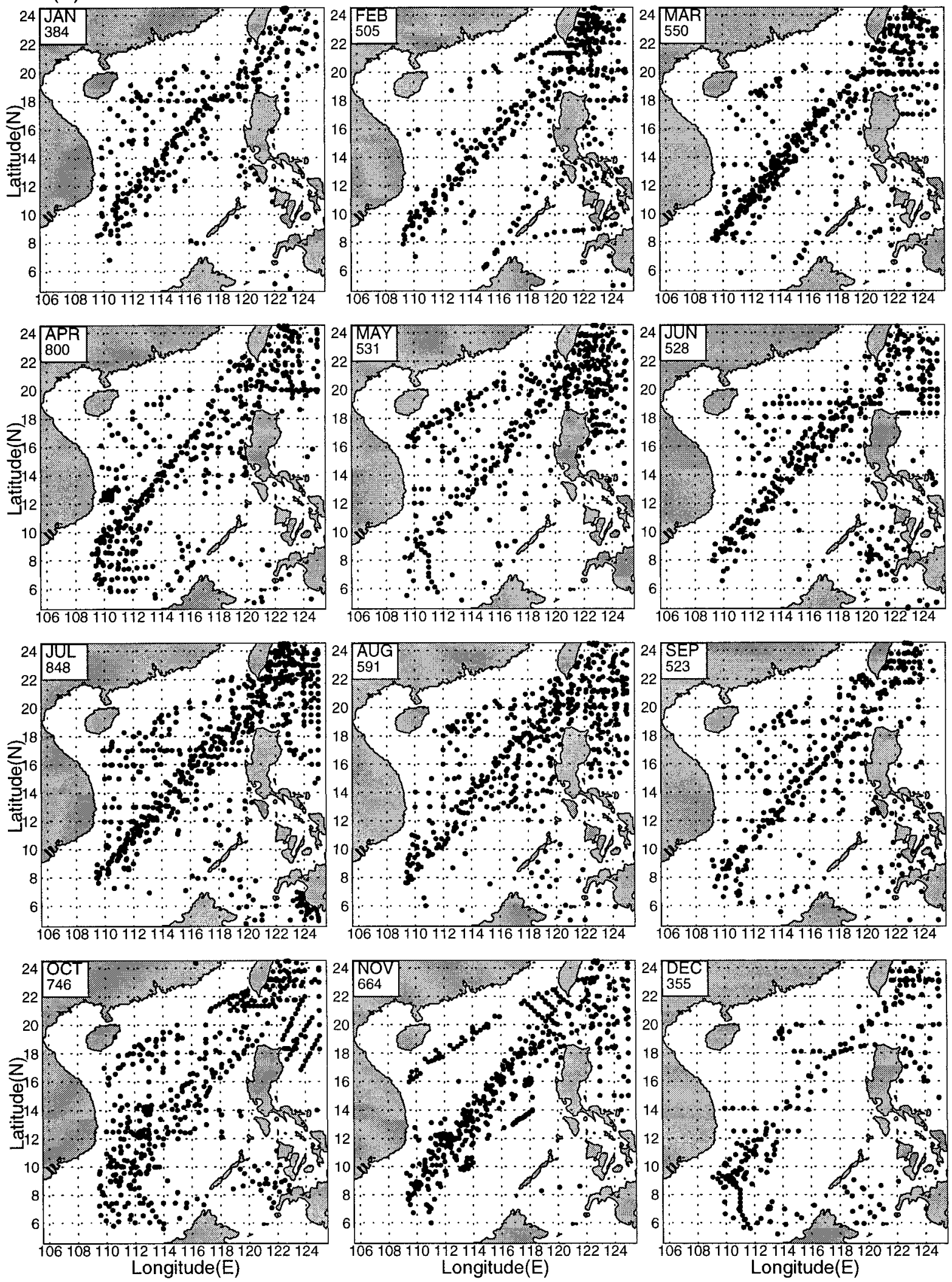

FIG. 2. (Continued) 

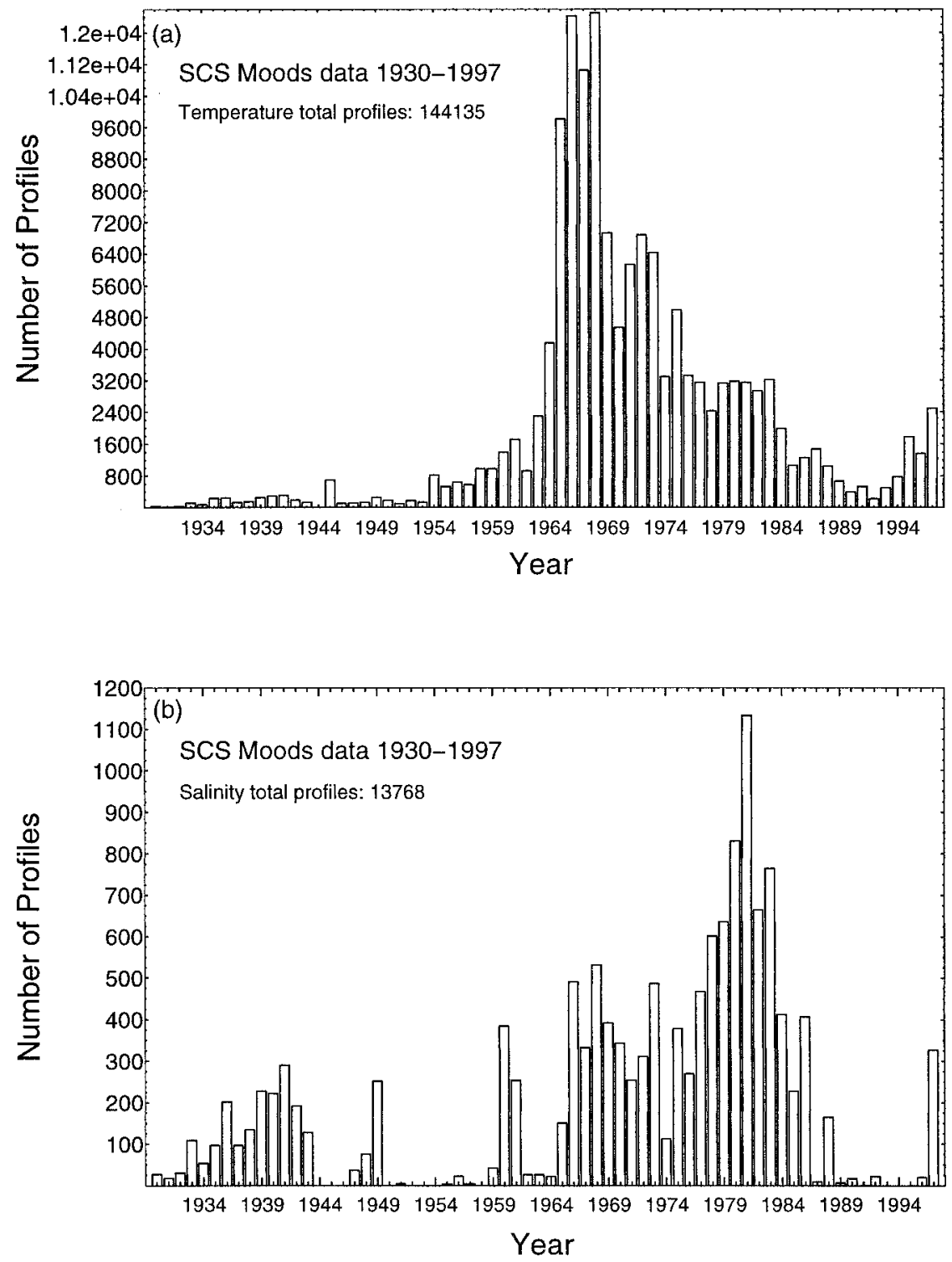

FIG. 3. Temporal distributions of MOODS stations during 1930-97: (a) temperature and (b) salinity.

The adiabatic density conservation and incompressible continuity equations are combined to give an equation for $\partial p / \partial \rho$. For the steady state, the equation is

$$
\frac{\partial}{\partial x}\left(\frac{\partial p}{\partial \rho} u\right)+\frac{\partial}{\partial y}\left(\frac{\partial p}{\partial \rho} v\right)=0 .
$$

Notice that the differentiations with respect to $x$ and $y$ are on the isopycnal surface. Equations (1)-(3) are the basic equations for the inversion.

Differentiation of (1) with respect to $\rho$ and use of (2) lead to the thermal wind relation

$$
\frac{\partial u}{\partial \rho}=\frac{1}{f \rho^{2}} \frac{\partial p}{\partial y}, \quad \frac{\partial v}{\partial \rho}=-\frac{1}{f \rho^{2}} \frac{\partial p}{\partial x} .
$$

\section{b. Tangential unit vector}

From (3) we define a streamfunction $\Psi(x, y)$ by

$$
f u=-\frac{q}{g} \frac{\partial \Psi}{\partial y}, \quad f v=\frac{q}{g} \frac{\partial \Psi}{\partial x},
$$

where $g$ is the gravitational acceleration and

$$
q=f g\left(\frac{\partial p}{\partial \rho}\right)^{-1}
$$

is the potential vorticity in the isopycnal coordinate system. Neglect of relative vorticity in the $q$ computation may induce a small but systematic error into estimation 


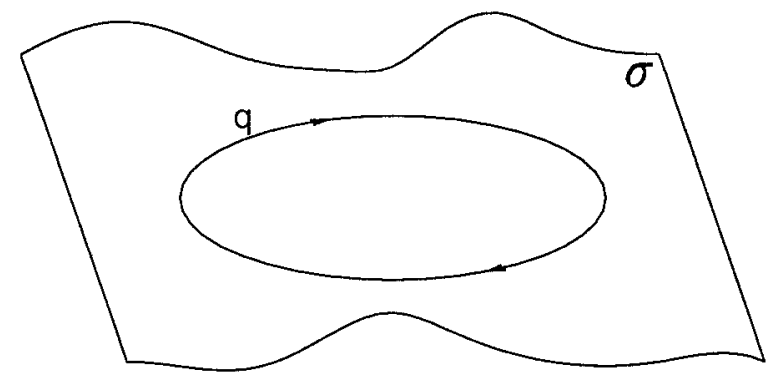

FIG. 4. Isoline of potential vorticity $(q)$ is the trajectory on the isopycnal surface.

of potential vorticity (G. T. Needler 1986, unpublished manuscript). From (1) and (5) we have

$$
\frac{\partial \Psi / \partial x}{\partial M / \partial x}=\frac{\partial \Psi / \partial y}{\partial M / \partial y}
$$

which implies that for a given $\rho$ the streamfunction $\Psi$ is a function of the Montgomery potential $M$ only, $\Psi$ $=\Psi(M)$. Thus, Eq. (5) becomes

$$
f u=-\frac{q}{g} \Psi^{\prime}(M) \frac{\partial M}{\partial y}, \quad f v=\frac{q}{g} \Psi^{\prime}(M) \frac{\partial M}{\partial x} .
$$

Comparing (7) to (1) we have

$$
q=\frac{g}{\Psi^{\prime}(M)} \equiv q(M)
$$

which implies that for a given $\rho$ the potential vorticity $q$ is a function of $M$ only, and in turn leads to the conservation of potential vorticity on the isopycnal surface,

$$
u \frac{\partial q}{\partial x}+v \frac{\partial q}{\partial y}=0
$$

The potential vorticity conservation leads to the fact that any water particle should move along $q$ isolines on the isopycnal surface, that is, any $q$ isoline is a trajectory of water particles (Fig. 4). For each trajectory, we can define a unit tangential vector,

$$
\mathbf{c}=\frac{1}{|\nabla q|}\left(\frac{\partial q}{\partial y} \mathbf{i}-\frac{\partial q}{\partial x} \mathbf{j}\right) .
$$

Such a two-dimensional vector, c, is equivalent to the earlier defined P vector on $z$ levels (Chu 1995; Chu et al. 1998a,b). The necessary condition for the existence of the vector $\mathbf{c}$ is

$$
\nabla q \neq 0 .
$$

At any point on the isopycnal surface, the vector c $=\left(c_{x}, c_{y}\right)$ indicates the tangential direction of the trajectory and therefore, is parallel to the absolute velocity vector,

$$
\mathbf{V}=\gamma(x, y, \rho) \mathbf{c}
$$

where the absolute value of $\gamma$ is the speed, $|\gamma|=|\mathbf{V}|$.

\section{c. Determination of the proportionality $\gamma$}

Applying the thermal wind relation (4) to any two different isopycnal levels $\rho_{k}$ and $\rho_{m}$, a set of algebraic equations for determining the parameter $r$ is obtained:

$$
\begin{aligned}
& \gamma^{(k)} c_{x}^{(k)}-\gamma^{(m)} c_{x}^{(m)}=\Delta u_{k m} \\
& \gamma^{(k)} c_{y}^{(k)}-\gamma^{(m)} c_{y}^{(m)}=\Delta v_{k m},
\end{aligned}
$$

which are two linear algebraic equations for $\gamma^{(k)}$ and $\gamma^{(m)}$. Here $\gamma^{(i)}=\gamma\left(x, y, \rho_{i}\right)$, and

$$
\left(\Delta u_{k m}, \Delta v_{k m}\right)=\frac{1}{f} \int_{\rho_{m}}^{\rho_{k}} \frac{1}{\rho^{2}}\left(\frac{\partial p}{\partial y},-\frac{\partial p}{\partial x}\right) d \rho .
$$

As soon as $\gamma^{(k)}$ is obtained, the velocity field can be computed by (11).

If the determinant

$$
\left|\begin{array}{cc}
c_{x}^{(k)} & c_{x}^{(m)} \\
c_{y}^{(k)} & c_{y}^{(m)}
\end{array}\right| \neq 0
$$

the algebraic equations (12) have definite solutions for $\gamma^{(k)}(m \neq k)$ :

$$
\gamma^{(k)}=\frac{\left|\begin{array}{ll}
\Delta u_{k m} & c_{x}^{(m)} \\
\Delta v_{k m} & c_{y}^{(m)}
\end{array}\right|}{\left|\begin{array}{ll}
c_{x}^{(k)} & c_{x}^{(m)} \\
c_{y}^{(k)} & c_{y}^{(m)}
\end{array}\right|} .
$$

Now, the velocity inversion can be divided into two steps: (i) determination of the unit vector c, and (ii) determination of $\gamma$. Chu et al. (1998a,b) show the advantage of this treatment in the velocity inversion. For water columns satisfying the two necessary conditions (10) and (13), we may use (14) to compute $\gamma^{(k)}$ for the level $\rho_{k}$. There are $N-1$ sets $(m=1,2, k-1, k+$ $1, \ldots, N)$ of equations (12) for calculating $\gamma^{(k)}$. Here $N$ is the total number of vertical levels of the water column. All the $N-1$ sets of equations are compatible under the thermal wind constraint and should provide the same solution. However, because of errors in measurements (instrumentation errors) and computations (truncation errors), the parameters $\gamma^{(k)}$ may vary with $m$. A least squares error algorithm was used to minimize the error. For further details and validation of the algorithm presented here see Chu et al. (1998a,b). (Interested readers can obtain the software by contacting Mr. C. Fan at fan@nps.navy.mil or online at http:// web.nps.navy.mil/ chu.)

\section{Monthly mean thermohaline fields}

The monthly mean three-dimensional temperature and salinity fields obtained from the GDEM dataset is similar to the climatological monthly mean fields directly computed from the MOODS as depicted in Chu et al. (1999). The sea surface temperature (SST) vari- 
ation obtained from the GDEM data is quite consistent with earlier investigations based on NCEP data (Chu et al. 1997a) and based on the MOODS data (Chu et al. $1997 b, 1999)$. It is not our intention to present a detail SCS climatological thermohaline structure in this paper. We only show some representative features at 150-m depth as illustration.

\section{a. Temperature}

Figure 5 is the horizontal depiction of monthly mean temperature at $150-\mathrm{m}$ depth. The contour interval is $0.5^{\circ} \mathrm{C}$. In them, we see that the SCS basin is dominated by a cool pool with several cold centers located northwest of Luzon and south of Dongsha (DS), near South Vietnamese Bight (SVB), Xisha (XS), and Liyue Bank. All of these cold centers were previously identified by an airborne expandable bathythermograph survey (Chu et al. 1998a) and statistical analysis on the MOODS data (Chu et al. 1997a, 1999). However, the individual cold center was observed much earlier. For example, Dale (1956) and Uda and Nakao (1972) reported a cold eddy off the central Vietnam Bight in the summer (i.e., the SVB cold center). Nitani (1970) found a cold eddy located northwest of Luzon in summer (DS cold center). The summer SVB and DS cold centers were also simulated by Chao et al. (1996) using a primitive equation model. The warm water appears in the vicinity of the SCS cool water. A transient central SCS warm pool was identified in spring (Chu et al. 1997a,b). A warm water mass is situated in the Philippine Sea all year round east of the Luzon Strait, where a strong front appears between the warm Kuroshio water and cool SCS water. Other two warm centers appear southwest of Luzon (SWL), and northwest of Borneo.

The SCS seasonal thermal variability can be characterized by strengthening/weakening of the major SCS cool pool. The basin-wide cool pool expands during the winter and shrinks during the summer. In December, this cool pool occupies the vast area of SCS from $9^{\circ}$ to $20^{\circ} \mathrm{N}$ with two evident cold centers: the Northwest Luzon cold center (located at $116^{\circ}-120^{\circ} \mathrm{E}, 16^{\circ}-19^{\circ} \mathrm{N}$ ) strengthens during the winter monsoon season and however, the Xisha cold center weakens and disappears in February and March. On the other hand, the SVB cold center (located at $109^{\circ}-112^{\circ} \mathrm{E}, 12^{\circ}-16^{\circ} \mathrm{N}$ ) appears in May and strengthens during the summer monsoon season, and at the same time the Northwest Luzon cold center weakens and disappears.

The warm tongue penetrates northwestward right after passing through the Luzon Strait from the Kuroshio and then stretches southwestward along the western boundary of the SCS with a very narrow width (100$200 \mathrm{~km})$. This is consistent with earlier research on climatological data (Shaw 1989, 1991) and in situ observational data (Li et al. 1998).

The SWL warm center (located at $116^{\circ}-120^{\circ} \mathrm{E}, 12^{\circ}-$ $14^{\circ} \mathrm{N}$ ) occurs in March. The warm tongue associated with the SWL warm center expands westward during the spring-to-summer transition, and occupies the east part of central SCS basin in the summer monsoon season (June-September). During the autumn-to-winter transition (October-November) the XS cold center occurs and strengthens in December.

\section{b. Salinity}

Figure 6 is the horizontal depiction of monthly mean salinity at $150-\mathrm{m}$ depth. The contour interval is 0.05 psu. The most evident feature is the advance/retreat of the salty tongue represented by a 34.60-psu isoline from the Philippine Sea through Luzon Strait. This salty tongue penetrates northwestward right after passing through the Luzon Strait and then stretches southwestward along the western boundary of the SCS. The salty tongue has the minimum penetration into the SCS in October. As the salt tongue advances into the northwestern SCS along the Chinese-Vietnamese coast, a salty center occurs near Dongsha $\left(115^{\circ}-117^{\circ} \mathrm{E}, 19^{\circ}-\right.$ $21^{\circ} \mathrm{N}$ ) in December. As the salty tongue further advances in the next six months (January-June), the Dongsha salty center weakens and disappears in March, and an evident salty center shows up near the SVB $\left(110^{\circ}-\right.$ $113^{\circ} \mathrm{E}, 14^{\circ}-16^{\circ} \mathrm{N}$ ) for six months (January-June) with salinity greater than 34.7 psu in February, March, April, and greater than 34.65 psu in other months. June is characterized as the maximum penetration of the salty tongue into the SCS. The salty tongue starts to retreat in July and the SVB salty center weakens. A salty center appears in southeastern SCS west of Palawan-Borneo $\left(114^{\circ}-116^{\circ} \mathrm{E}, 8^{\circ}-11^{\circ} \mathrm{N}\right)$ enclosed by $34.6 \mathrm{psu}$. This salty center expands toward the west until December.

Such a feature is somewhat inconsistent with the earlier studies (e.g., Shaw 1991). This is due to the sparse salinity observations in the SCS. The MOODS dataset for building the GDEM climatology has much less salinity than temperature stations (Fig. 2). The seasonal variability depicted here is not reliable for certain regions such as the region between Liyue bank and Nansha, where there is no observational data.

\section{Computation in the isopycnal coordinate system}

\section{a. Vertical discretization}

Following earlier studies (e.g., Keffer 1985; Tally 1988), we use three reference levels for potential density computation: $\sigma_{\theta}$ for the surface, $\sigma_{2}$ for 2000 decibar $(\mathrm{db})$, and $\sigma_{4}$ for $4000 \mathrm{db}$. Use of $\sigma_{2}$ and $\sigma_{4}$ provides a better potential vorticity representation for levels near 2000 and $4000 \mathrm{db}$, respectively. Here,

$$
\sigma_{m}=\rho_{m}-1000 \mathrm{~kg} \mathrm{~m}^{-3}, \quad m=0,2,4,
$$

where $\sigma_{0} \equiv \sigma_{\theta}$. The potential density $\sigma_{\theta}, \sigma_{2}$, and $\sigma_{4}$ represent upper, intermediate, and deep layers, respectively. We consider the following ranges for the $\sigma_{m}$-values: 

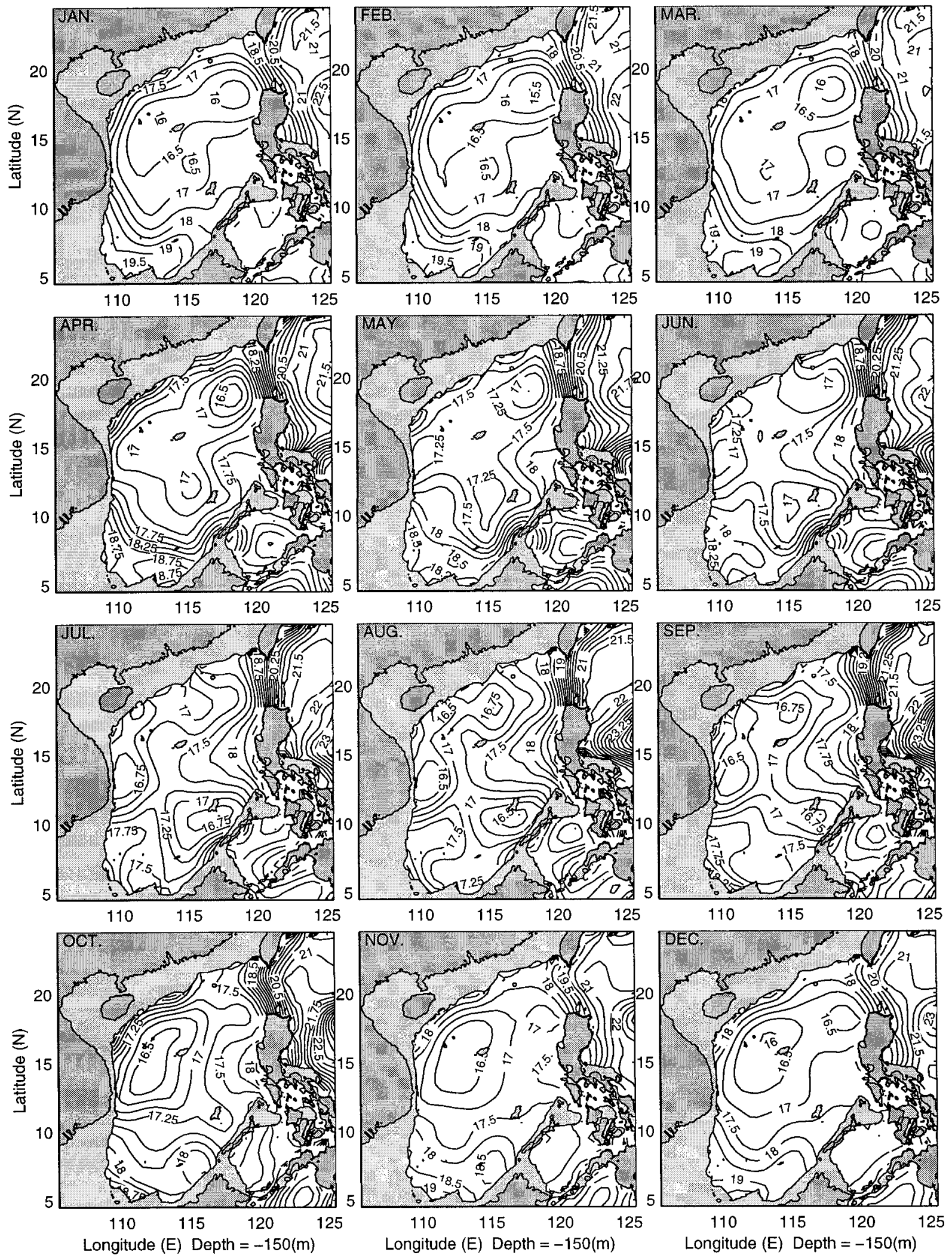

FIG. 5. Monthly mean temperature $\left({ }^{\circ} \mathrm{C}\right)$ fields at $150-\mathrm{m}$ depth obtained from the GDEM. 

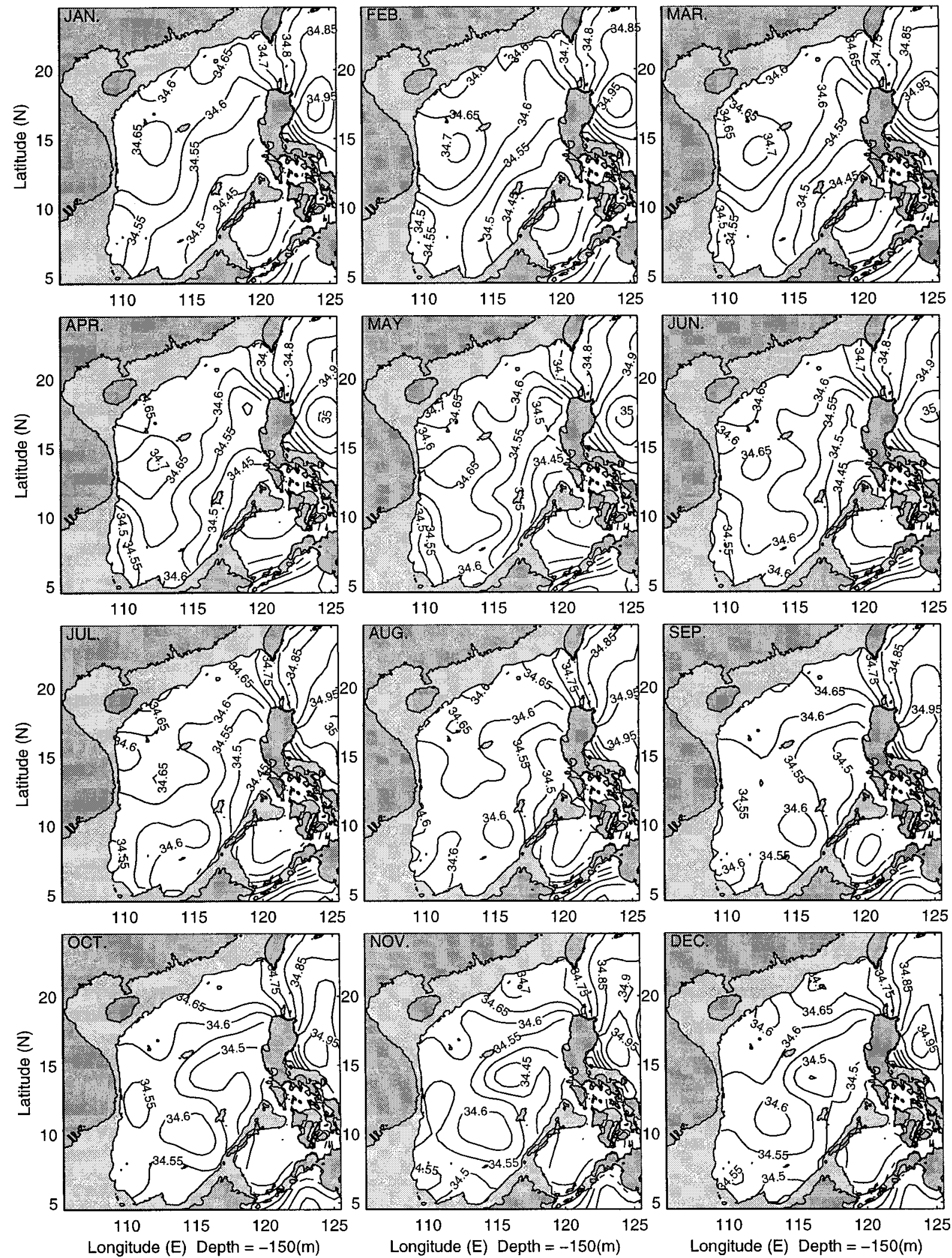

FIG. 6. Monthly mean salinity (psu) fields at 150-m depth obtained from the GDEM. 


$$
\begin{aligned}
22.200 & \leq \sigma_{\theta} \leq 27.725, \quad 31.625 \leq \sigma_{2} \leq 37.150, \\
41.30 & \leq \sigma_{4} \leq 45.90 .
\end{aligned}
$$

Notice that the values of $27.725,37.15,45.90$ are maximum values for $\sigma_{0}, \sigma_{2}$, and $\sigma_{4}$ computed from the GDEM $T, S$ dataset. We further discretize $\sigma_{0}, \sigma_{2}$, and $\sigma_{4}$ with the same increment,

$$
\Delta \sigma=0.025 \mathrm{~kg} \mathrm{~m}^{-3},
$$

for $\sigma_{0}$ and $\sigma_{2}$, and

$$
\Delta \sigma=0.02 \mathrm{~kg} \mathrm{~m}^{-3}
$$

for $\sigma_{4}$. Thus, we have $222 \sigma_{\theta}$-layers, $222 \sigma_{2}$-layers, and $280 \sigma_{4}$-layers. Within each layer, the density is vertically uniform.

In order to well resolve isopycnal surfaces, we use cubic spline to interpolate the $T, S$ data into $246 z$ levels with three different increments: $5 \mathrm{~m}$ from 0 - to $100-\mathrm{m}$ depth, $10 \mathrm{~m}$ from 100 - to $1000-\mathrm{m}$ depths, $20 \mathrm{~m}$ from 1000 - to 2500-m depths, and $50 \mathrm{~m}$ below 2500-m depths. Thus, we build up a high resolution $z$-coordinate data set $\left[\hat{T}\left(z_{j}\right), \hat{S}\left(z_{j}\right), \hat{\sigma}_{\theta}\left(z_{j}\right)\right]$. The symbol overcarat indicates either the observational data or the values computed from the observational data. Notice that the values of 27.725 is the maximum value for $\sigma_{\theta}$, computed from the GDEM $T, S$ dataset. For simplicity and no loss of generality, we will use $\sigma_{\theta}$ for illustration.

\section{b. Transformation of $T, S$ data from a $z$ to $\sigma_{\theta}$ coordinate system}

The transformation is fulfilled by comparing the $z$-coordinate potential density data $\hat{\sigma}_{\theta}\left(z_{j}\right)$ with the discrete $\sigma_{\theta}$-values at the bottom of the $k$ th-isopycnal layer, $\sigma_{\theta}^{b}(k)$

$$
\begin{aligned}
\sigma_{\theta}^{b}(k) & =22.1875+(k-1) \Delta \sigma_{\theta}, \\
\sigma_{\theta}(k) & =\frac{1}{2}\left[\sigma_{\theta}(k)+\sigma_{\theta}(k+1)\right] .
\end{aligned}
$$

The geometric depth for the bottom of the $\sigma_{\theta}(k)$-layer is obtained by

$$
\begin{aligned}
\hat{D}_{k}^{b}=-z_{j}, & \text { if } \hat{\sigma}_{\theta}\left(z_{j}\right)=\sigma_{\theta}^{b}(k) \text { and } \\
\hat{D}_{k}^{b}=-z_{j}- & \frac{\sigma_{\theta}(k)-\hat{\sigma}_{\theta}\left(z_{j}\right)}{\hat{\sigma}_{\theta}\left(z_{j+1}\right)-\hat{\sigma}_{\theta}\left(z_{j}\right)}\left(z_{j+1}-z_{j}\right), \\
& \text { if } \hat{\sigma}_{\theta}\left(z_{j}\right)<\sigma_{\theta}^{b}(k)<\hat{\sigma}_{\theta}\left(z_{j+1}\right),
\end{aligned}
$$

where the superscript $b$ indicates the bottom of the $k$ thisopycnal layer. The thickness of the $k$ th-isopycnal layer is obtained by

$$
\hat{h}_{k}=\hat{D}_{k}^{b}-\hat{D}_{k-1}^{b}
$$

\section{c. Pressure and potential vorticity computation}

After $\hat{h}_{k}$ is obtained, we may compute the pressure and potential vorticity fields. Starting from the surface

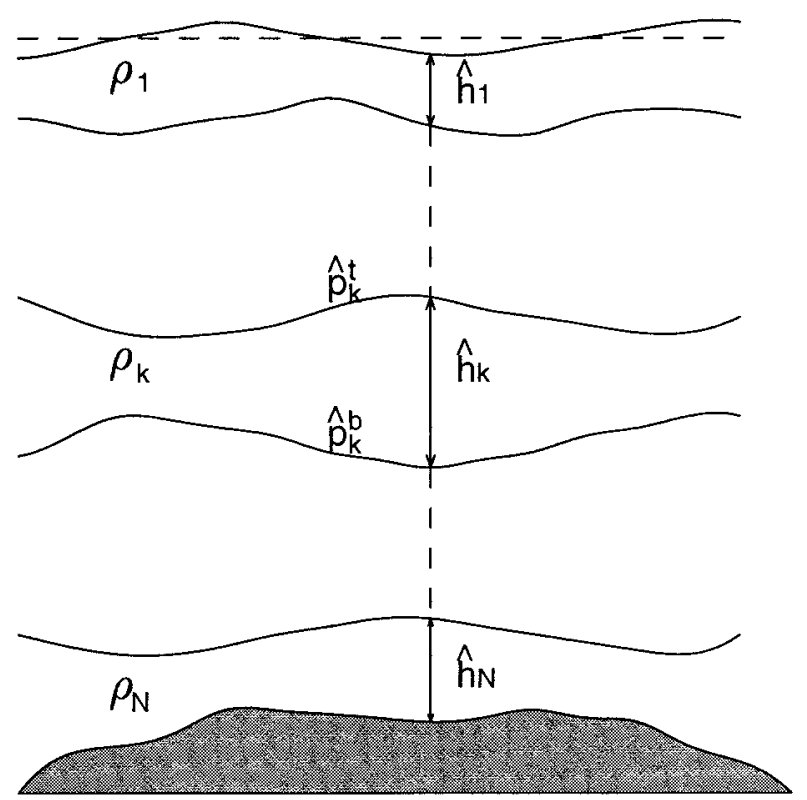

FIG. 7. The $k$ th-isopycnal layer.

$(k=1)$, the $k$ th layer has the density $\rho_{k}$, and thickness $\hat{h}_{k}$, as shown in Fig. 7. Since the pressure is not uniform within the layer, it has the value of

$$
\hat{p}_{k}^{t}=g \sum_{i=1}^{k-1} \rho_{i} \hat{h}_{i}
$$

at the top of the $k$ th layer, and the value of

$$
\hat{p}_{k}^{b}=g \sum_{i=1}^{k} \rho_{i} \hat{h}_{i}
$$

at the bottom of the $k$ th layer. We may use the average

$$
\hat{p}_{k} \equiv \frac{\hat{p}_{k}^{t}+\hat{p}_{k}^{b}}{2}=g\left(\sum_{i=1}^{k-1} \rho_{i} \hat{h}_{i}+\frac{1}{2} \rho_{k} \hat{h}_{k}\right)
$$

to indicate the pressure at the middle of the $k$ th layer. For the $k$ th-isopycnal layer $\sigma_{\theta}(k)$, the potential vorticity (6) is discretized by

$$
\hat{q}_{k}=\frac{f g \delta \sigma_{\theta}}{\hat{p}_{k}^{b}-\hat{p}_{k}^{t}} .
$$

Earlier work (e.g., McCartney 1982; Keffer 1985; Talley 1988) also shows the benefit of using potential vorticity in ocean circulation studies.

\section{Monthly mean circulations}

Most important features from our computation are the Kuroshio intrusion, basin gyre, flow separation, and mesoscale eddies. The inverted monthly SCS circulation agrees quite well with earlier observational study (Wyrtki 1961) at the surface and with modeling results (Chu et al. 1999) at the deeper levels. 
a. Subsurface $\left(\sigma_{\theta}=23.0 \mathrm{~kg} \mathrm{~m}^{-3}\right)$

The subsurface shows a strong seasonal variation (Fig. 8). Due to the shallowness of $\sigma_{\theta}=23$, the Kuroshio east of the Luzon Strait is not well inverted. Warm and salty Kuroshio water enters the SCS through the Luzon Strait evidently in October-March, the transition to and during the winter monsoon season. The winter circulation pattern is the basin-wide cyclonic gyre. A cyclonic mesoscale eddy splits from the gyre near DS in February, strengthens afterward, and becomes evident through the whole summer monsoon season. The Kuroshio intruded flow is likely to be confined near the continental slope south of China. The DS cyclonic eddy is undetectable from November to January. On the other hand, the basin-wide cyclonic gyre weakens in April with the disappearance of the southward western boundary currents near the Vietnamese coast.

The summer (June-August) pattern is generally a weak anticyclonic gyre. A northward western boundary current occurs from the south to the Vietnamese coast with a much weaker speed (less than $0.1 \mathrm{~m} \mathrm{~s}^{-1}$ ) than its counterpart (southward western boundary current) in the winter. The western boundary current splits into two currents at $10^{\circ} \mathrm{N}$ : the coastal current and the offshore current. The offshore current recirculates and forms a mesoscale anticyclonic eddy near Natuna Island (NI). The NI eddy was simulated using a numerical model (Chu et al. 1999). The coastal branch continues north then east at Hainan Island.

\section{b. Intermediate level $\left(\sigma_{\theta}=26.2 \mathrm{~kg} \mathrm{~m}^{-3}\right)$}

As the water depth increases, the seasonal variation of the inverted velocity reduces with depth. The intermediate level $\left(\sigma_{\theta}=26.2\right)$, changing from 280 to 460 $\mathrm{db}$, has a persistent basin-scale cyclonic gyre as the major feature of the circulation. There is no seasonal reversal of the western boundary current. The seasonal circulation variability is features by strengthening, weakening, and splitting of a basin-wide cyclonic gyre (Fig. 9). This gyre is evident and strong in the winter and weakens in the summer. As spring approaches (April-May), the western boundary currents (southward) near the SVB weakens. This "broken" gyre feature continues in the whole summer (June-August). The western boundary currents (southward) intensifies in the fall. The cyclonic basin-scale gyre all year round at the intermediate level consists with the numerical models (Metzger and Hurlburt 1996; Chu et al. 1999).

\section{Kuroshio intrusion through the Luzon Strait}

The seasonal variation of the intrusion of the Kuroshio Water into the SCS through the Luzon Strait has been investigated in earlier studies (Shaw 1989, 1991). As pointed out by Shaw (1991), the intrusion process is important not only to the transport of water masses into the SCS, but also to the shelf circulation off the southeast coast of China. Shaw (1989) used the discriminant analysis method to classify the water mass $T$, $S$ characteristics at 150,200 , and $250 \mathrm{~m}$, and found that water characteristics of the Philippine Sea (Kuroshio) were identifiable along the continental margin south of China from October to January. The presence of this water indicated an intrusion current from the Philippine Sea into the SCS.

We use the east-west geostrophic velocities on isopycnal surfaces along $120^{\circ} 45^{\prime} \mathrm{E}$ longitude with the minimum distance between Taiwan and Luzon to represent the flow across the Luzon Strait (Fig. 10). Positive values show the outflow from the SCS to the Philippine Sea, and negative values represent the inflow from the Philippine Sea to the SCS (Kuroshio intrusion). The estimate of the transport through the Luzon Strait is sensitive to the cross-section selection due to larger gradient of the property (temperature, salinity, and Montgomery potential, etc.) in the zonal direction than in the latitudinal direction. The signal of the zonal flow might be contaminated by the fluctuation of the Kuroshio.

Flow through the Luzon Strait has a strong seasonal variation in the upper and intermediate layers. Evident Kuroshio intrusion occurs from November to April from the surface to $\sigma_{\theta}=27.0$ with the maximum speed of $0.18 \mathrm{~m} \mathrm{~s}^{-1}$ in the middle of the Strait at $\sigma_{\theta}=23.75$ in December. From January to March the core of this jet splits into two jet cores. The upper jet core $\left(\sigma_{\theta}=24\right)$ shifts toward the south (Luzon Island) with the maximum speed reducing from $0.17 \mathrm{~m} \mathrm{~s}^{-1}$ (January) to 0.14 $\mathrm{m} \mathrm{s}^{-1}$ (March). The lower jet core $\left(\sigma_{\theta}=25\right)$ keeps the same location in the middle of the strait $\left(20^{\circ}-20^{\circ} 30^{\prime} \mathrm{N}\right)$. In the spring and summer, the Kuroshio intrusion weakens drastically. The maximum speed becomes $0.06 \mathrm{~m}$ $\mathrm{s}^{-1}$ at the intermediate level $\left(\sigma_{\theta}=26.0\right)$ in the southern part of the Luzon Strait (near $19.5^{\circ} \mathrm{N}$ ) from May to October. Weak outflow $\left(0.02 \mathrm{~m} \mathrm{~s}^{-1}\right)$ to the Philippine Sea occurs in the northern part of the Luzon Strait (north of $20^{\circ} 45^{\prime} \mathrm{N}$ ) from the surface to $\sigma_{\theta}=25.5$ during the summer monsoon season.

We computed monthly total and layered (between two $\sigma_{\theta}$ levels) volume transports through the Luzon Strait (Fig. 11). The dashed, dotted, and solid curves indicate outflow (eastward), inflow (westward), and net transports. The outflow is much weaker than the inflow for the total transport and the most layered transports except the deep layer $\left(\sigma_{\theta} \geq 27.025\right)$, where the outflow is dominant. The total transport is negative (inflow) all year round with a minimum value of $-13.7 \mathrm{~Sv}$ in February and a maximum value of $-1.4 \mathrm{~Sv}$ in September with the annual transport of $-6.5 \mathrm{~Sv}$; which is between Metzger and Hurlburt's (1996) estimation (2.4-4.4 Sv) and Huang et al.'s (1994) estimation (8-10 Sv). The total and layered volume transports at the Luzon Strait might be useful for SCS numerical modeling.

There is a time lag in seasonal variations between the Kuroshio intrusion and the salty tongue penetration (Fig. 

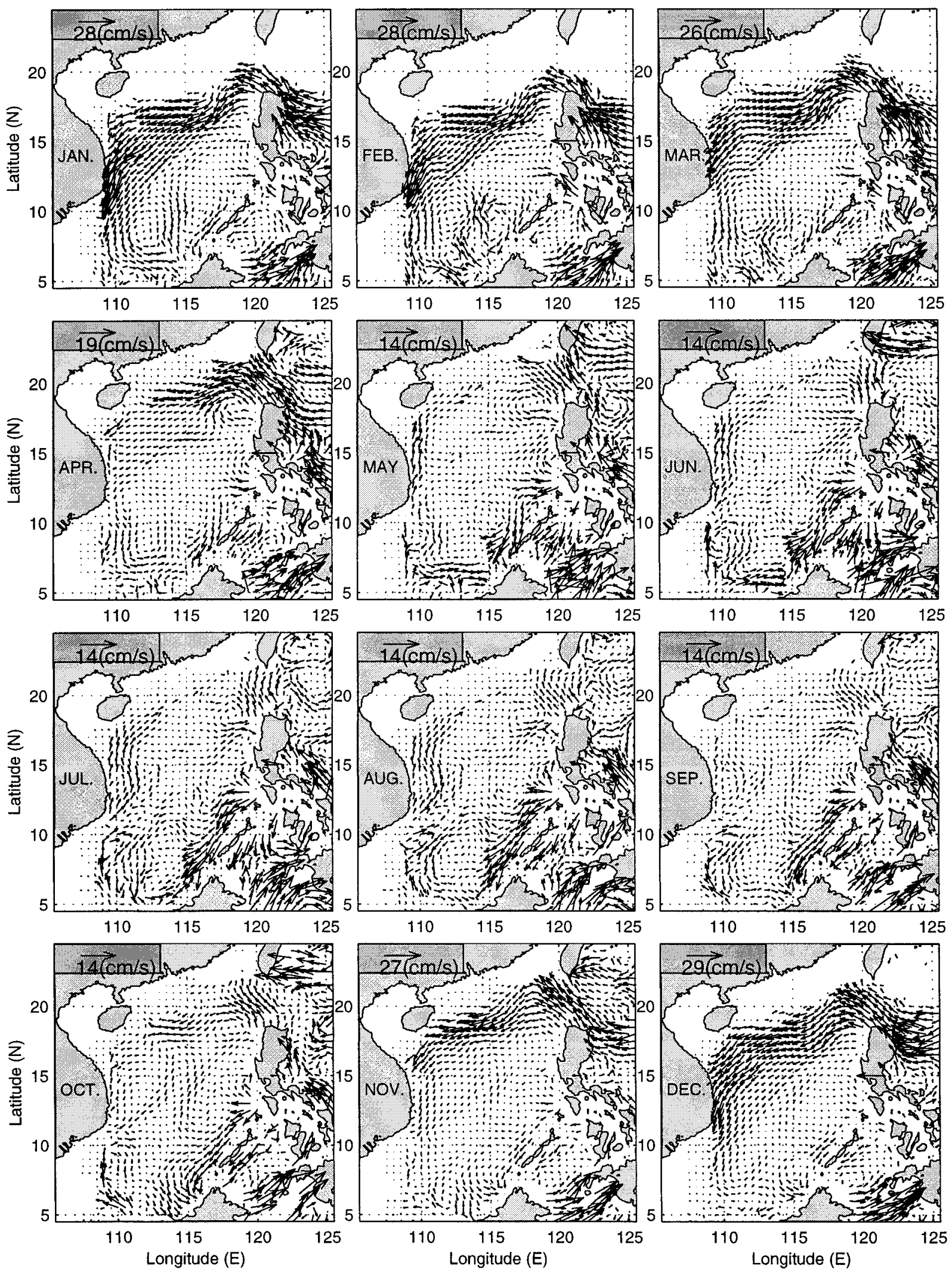

FIG. 8. Monthly mean subsurface $\left(\sigma_{\theta}=23.0 \mathrm{~kg} \mathrm{~m}^{-3}\right)$ velocity vector field. 

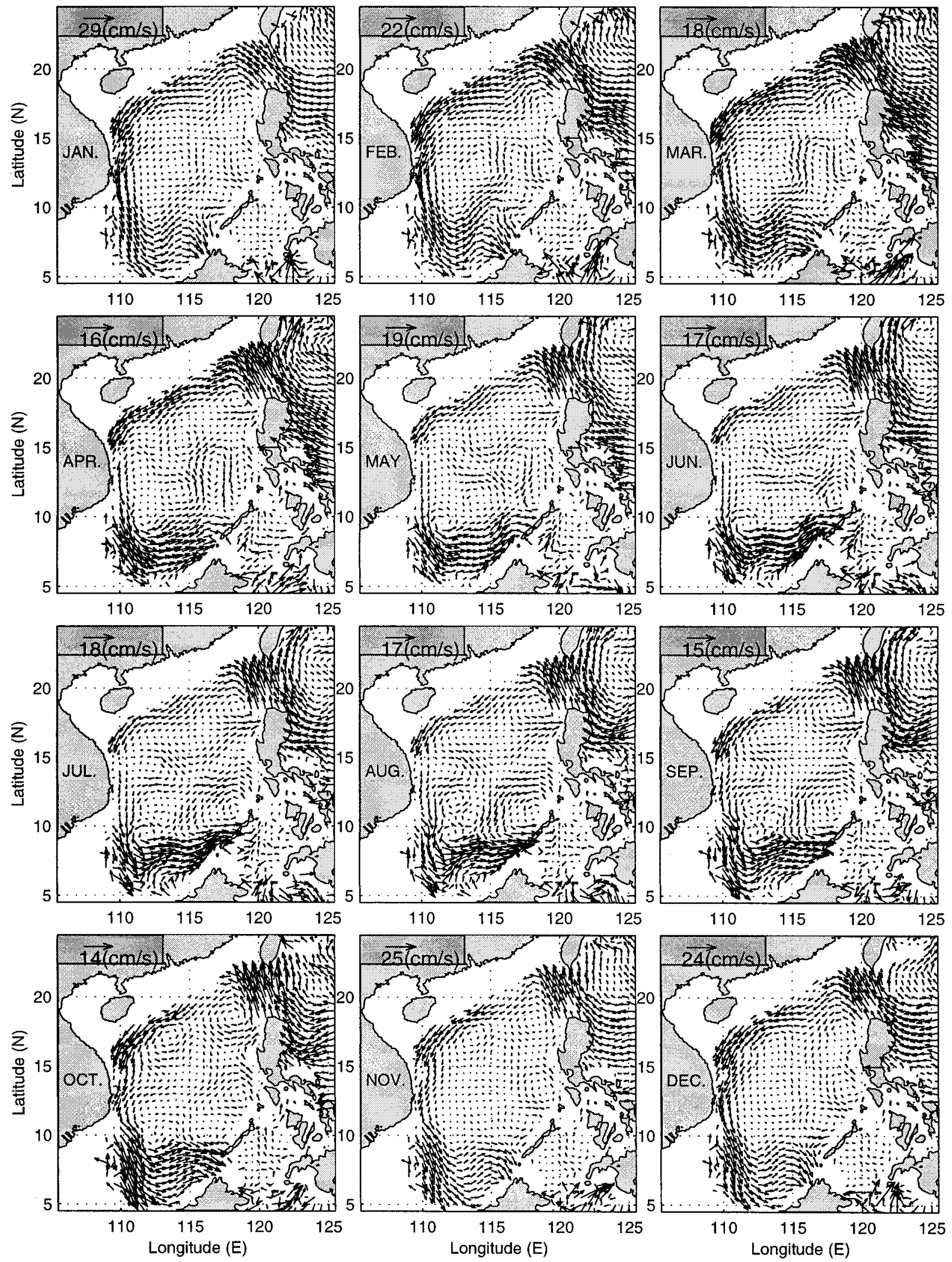

FIG. 9. Monthly mean intermediate level $\left(\sigma_{\theta}=26.2 \mathrm{~kg} \mathrm{~m}^{-3}\right)$ velocity vector field. 

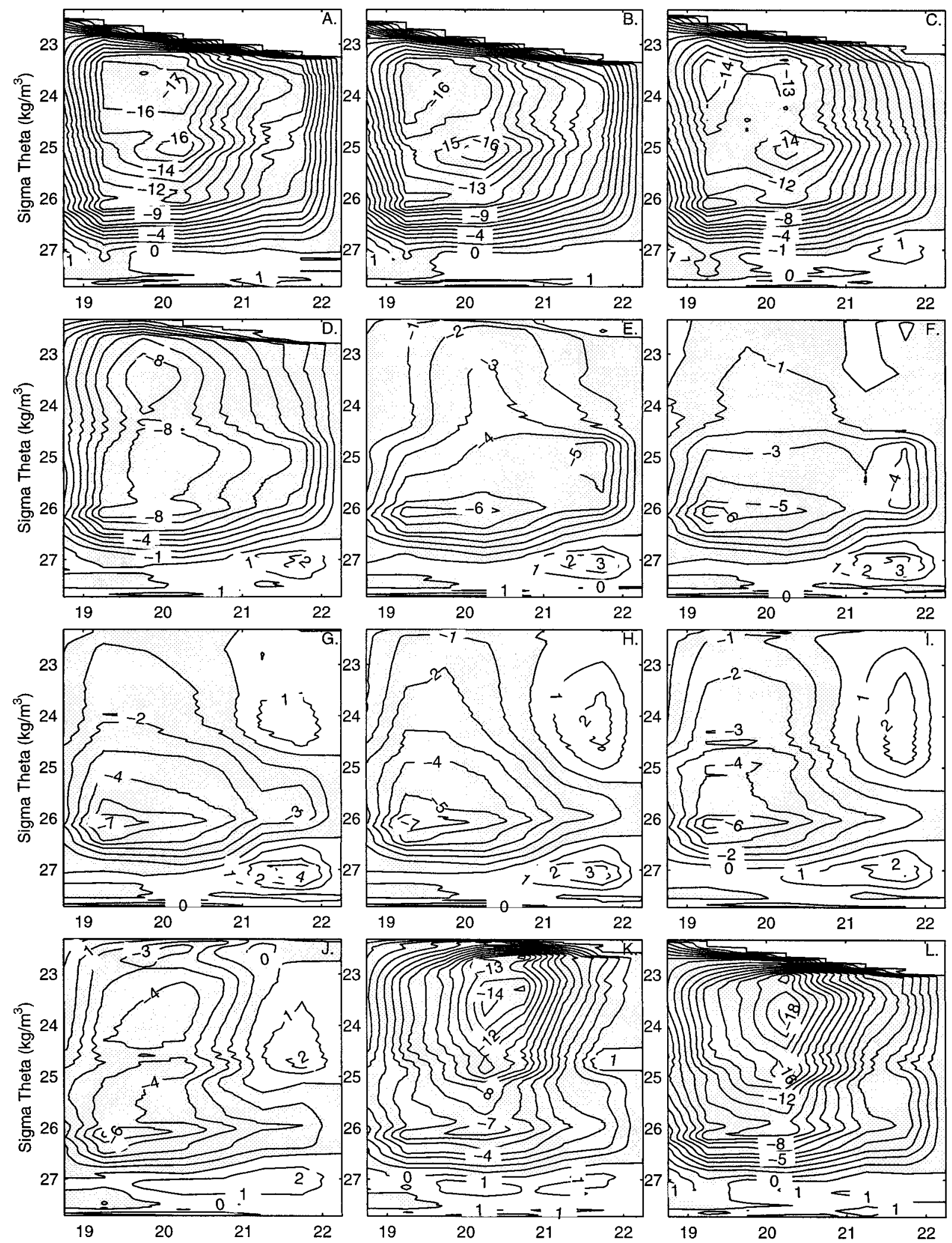

FIG. 10. Monthly mean east-west geostrophic velocities (eastward positive) on isopycnal surfaces along $120^{\circ} 45^{\prime} \mathrm{E}$ longitude representing the flow across the Luzon Strait (unit: $0.01 \mathrm{~m} \mathrm{~s}^{-1}$ ). 

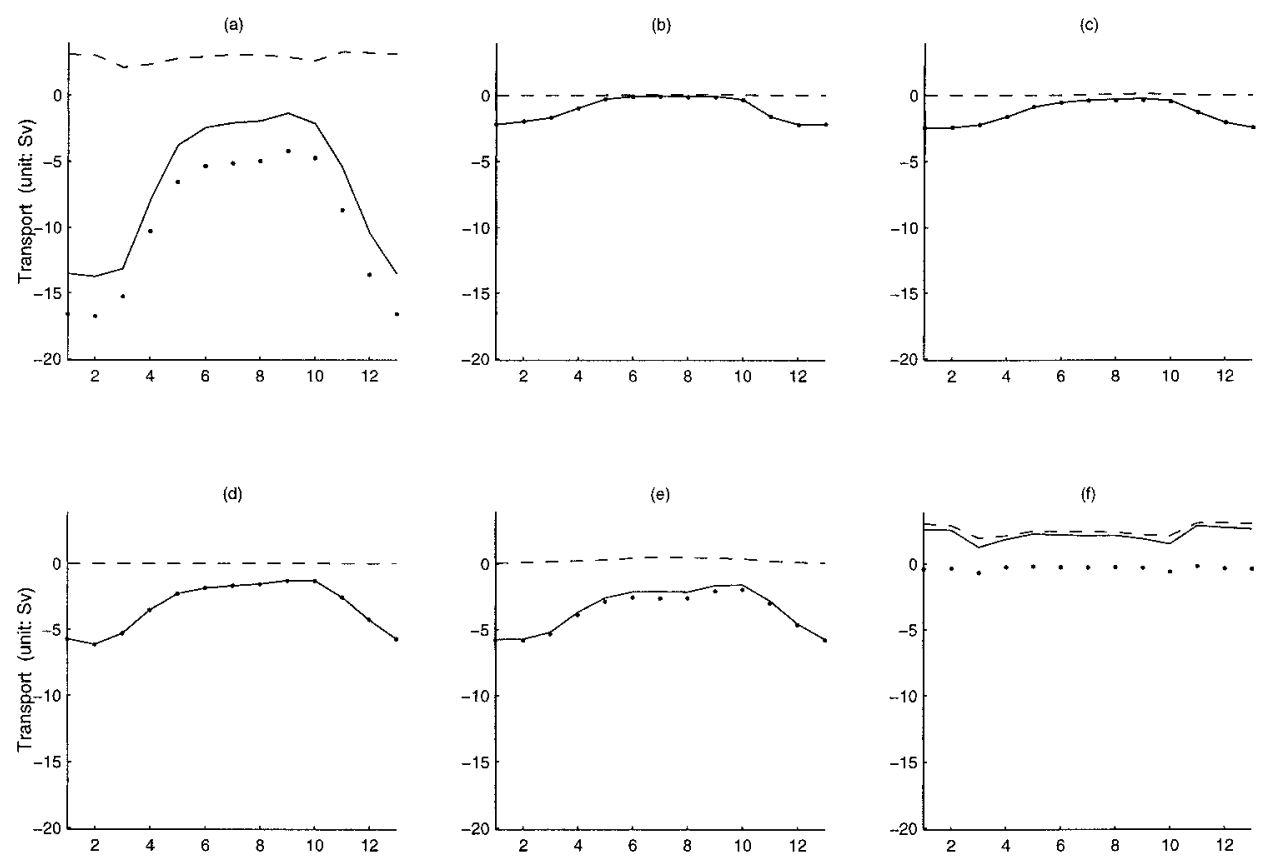

FIG. 11. Monthly total and layered (between two $\sigma_{\theta}$ levels) volume transports through the Luzon Strait along $120^{\circ} 45^{\prime} \mathrm{E}$ longitude: (a) total, (b) $\sigma_{\theta}$ less than 24.0, (c) $\sigma_{\theta}$ from 24.0 to 25.0 , (d) $\sigma_{\theta}$ from 25.0 to 26.0 , (e) $\sigma_{\theta}$ from 26.0 to 27.0 , and (f) $\sigma_{\theta}$ more than 27.0. The dashed, dotted, and solid curves indicate the outflow (eastward), the inflow (westward), and the net transports.

6) at 150-m depth (around $25.0 \sigma_{\theta}$ surface): the Kuroshio intrusion (Fig. 10) is the strongest in January, and the salty tongue (Fig. 6) has the maximum penetration in June. Such a lag (4-5 months) is approximately the travel time for the Kuroshio water penetrating from the Luzon Strait into the southern SCS. For a rough estimation, water particles in the winter (DecemberFebruary) enter the Luzon Strait with a speed around of $0.10 \mathrm{~m} \mathrm{~s}^{-1}$ at $150-\mathrm{m}$ depth and travel $8.64 \mathrm{~km}$ each day. The distance between the Luzon Strait and the southern SCS is nearly $1200-1400 \mathrm{~km}$. It will take approximately 5 months for the water particles traveling from the Luzon Strait to reach the southern SCS.

\section{Conclusions}

The goal of this study is to investigate the seasonal circulation patterns of the South China Sea on isopycnal surfaces using the navy's unclassified GDEM data on $1 / 2^{\circ} \times 1 / 2^{\circ}$ resolution. We reformulate the P-vector inverse method for determining the absolute geostrophic velocity on the isopycnal surface. The circulation pattern agrees quite well with earlier observational (Wyrtki 1961; Chu et al. 1997a,b; Chu et al. 1998b) and modeling studies (Metzger and Hurlburt 1996; Chu et al. 1998c, 1999).

(1) The GDEM data at intermediate depth $(150 \mathrm{~m})$ shows that the SCS basin is dominated by a cool pool with several cold centers located northwest of Luzon and south of Dongsha, near the South Vietnamese Bight,
Xisha, and Liyue Bank. The warm water appears in the vicinity of the SCS cool water. Two other warm centers appear southwest of Luzon, and northwest of Borneo. The SCS seasonal thermal variability is characterized by strengthening/weakening and expanding/shrinking of the major SCS cool pool. The basin-wide cool water expand during the winter and shrinks during the summer. In December, this cool pool occupies the vast area of the SCS from $9^{\circ}$ to $20^{\circ} \mathrm{N}$. The warm tongue penetrates northwestward through the Luzon Strait from the Kuroshio and then stretches southwestward along the western boundary of the SCS with a very narrow width (100-200 km).

(2) The GDEM data at intermediate depth $(150 \mathrm{~m})$ shows the advance/retreat of the salty tongue represented by 34.60 psu isoline from the Philippine Sea through the Luzon Strait. This salty tongue penetrates northwestward right after passing through the Luzon Strait and then stretches southwestward along the western boundary of the SCS. The salty tongue has the maximum (minimum) penetration into the SCS in June (October).

(3) The subsurface $\left(\sigma_{\theta}=23.0 \mathrm{~kg} \mathrm{~m}^{-3}\right)$ circulation has a strong seasonal variation with a basin-wide cyclonic gyre in the winter and a weak anticyclonic gyre in the summer. Warm and salty Kuroshio water enters the SCS through the Luzon Strait evidently in OctoberMarch, the transition to and during the winter monsoon season. A cyclonic mesoscale eddy splits from the gyre near Dongsha in February, strengthens afterwards, and 
becomes evident through the whole summer monsoon season. The Kuroshio intruded flow is the north or the northeast fringe of the DS eddy. The maximum speed reaches $0.2 \mathrm{~m} \mathrm{~s}^{-1}$ in April. The Dongsha cyclonic eddy is undetectable from November to January. During the summer, the northward western boundary current occurs from the south to the Vietnamese coast with a much weaker speed (less than $0.1 \mathrm{~m} \mathrm{~s}^{-1}$ ) in the summer than its counterpart (southward western boundary current) in the winter. The western boundary current splits into two currents at $10^{\circ} \mathrm{N}$. The offshore current recirculates and forms a mesoscale anticyclonic eddy near Natuna Island. The major feature of the circulation at the intermediate level $\left(\sigma_{\theta}=26.2\right)$ is the persistence of the basin-scale cyclonic gyre. There is no seasonal reversal of the western boundary current. The gyre is evident and strong in the winter and weakens in the summer. As spring approaches (April-May), the western boundary currents (southward) near the SVB weakens. This "broken" gyre feature continues in the whole summer (June-August). The western boundary currents (southward) intensifies in the fall.

(4) We computed monthly total and layered (between two $\sigma_{\theta}$ levels) volume transports through the Luzon Strait along $120^{\circ} 45^{\prime} \mathrm{E}$ longitude. The outflow is much weaker than the inflow for the total transport and the most layered transports except the deep layer $\left(\sigma_{\theta} \geq\right.$ 27.025), where the outflow is dominant. The total transport is negative (inflow) all year round with a minimum value of $-13.7 \mathrm{~Sv}$ in February (strongest intrusion) and a maximum value of $-1.4 \mathrm{~Sv}$ in September (weakest intrusion) with the annual transport of $-6.5 \mathrm{~Sv}$. These values may change when different cross section is used.

(5) Current ocean numerical models are initialized from either observed or climatological temperature and salinity, as well as zero velocity. This leads to an imbalance between the velocity and density fields during the spinup period. If we use the geostrophic velocity, as the initial condition, the velocity and density fields are balanced. Thus, the inverse method proposed here provides a better initialization for the isopycnal models.

(6) Two important parameters, volume transport through the Taiwan Strait and wind stress, are not included in this study. Exclusion of the volume transport through the Taiwan Strait is due to the difficulty of the inversion on the isopycnal surface in shallow depths. Without the wind stress, the circulation presented here is only the geostrophic flow. Chu et al. (1998c) showed that the wind stress largely affects the seasonal variabilities (especially in the circulation) in upper layer (30 $\mathrm{m})$ of SCS. Thus, if the wind stress is considered, the seasonal variabilities at the sub-surface $\left(\sigma_{\theta}=23.0 \mathrm{~kg}\right.$ $\mathrm{m}^{-3}$ ) are expected to be larger. Inclusion of wind stress in the velocity inversion is one of our on-going projects.

Acknowledgments. The authors wish to thank Chenwu Fan at the Naval Postgraduate School for computational assistance. This work was funded by the Office of Naval
Research NOMP Program, the Naval Oceanographic Office, and the Naval Postgraduate School. Rongfeng Li was partially sponsored by the Chinese National Science Foundation.

\section{REFERENCES}

Bleck, R., and L. Smith, 1990: A wind-driven isopycnic coordinate model of the north and equatorial Atlantic Ocean. 1: Model development and supporting experiments. J. Geophys. Res., 95, 3273-3285.

Chao, S.-Y., P.-T. Shaw, and S. Y. Wu, 1996: Deep water ventilation in the South China Sea. Deep-Sea Res., 43, 445-466.

Chu, P. C., 1995: P vector method for determining absolute velocity from hydrographic data. Mar. Technol. Soc. J., 29, 3-14.

— , and C. P. Chang, 1997: South China Sea warm pool in boreal spring. Adv. Atmos. Sci., 14, 195-206.

- C. C. Li, D. S. Ko, and C. N. K. Mooers, 1994: Response of the South China Sea to seasonal monsoon forcing. Proc. Second Int. Conf. on Air-Sea Interaction and Meteorology and Oceanography of the Coastal Zone, Lisbon, Portugal, Amer. Meteor. Soc., 214-215.

_- M. Huang, and E. Fu, 1996: Formation of the South China Sea warm core eddy in boreal spring. Proc. Eighth Conf. on AirSea Interaction, Atlanta, GA, Amer. Meteor. Soc., 155-159.

— S. H. Lu, and Y. C. Chen, 1997a: Temporal and spatial variabilities of the South China Sea surface temperature anomaly. J. Geophys. Res., 102, $20937-20955$.

— H. C. Tseng, C. P. Chang, and J. M. Chen, 1997b: South China Sea warm pool detected in spring from the navy's Master Oceanographic Observational Data Set (MOODS). J. Geophys. Res., 102, 15 761-15 771.

—, S. K. Wells, S. D. Haeger, C. Szczechowski, and M. Carron, 1997c: Temporal and spatial scales of the Yellow Sea thermal variability. J. Geophys. Res., 102, 5655-5667.

- C. W. Fan, and W. J. Cai, 1998a: Evaluation of $P$ vector method using modular ocean model (MOM). J. Oceanogr., 54, 185-198.

, - C. J. Lozano, and J. L. Kirling, 1998b: An airborne expandable bathythermograph survey of the South China Sea, May 1995. J. Geophys. Res., 103, 21 637-21 652.

_ Y. C. Chen, and S. H. Lu, 1998c: Wind-driven South China Sea deep basin warm-core/cool-core eddies. J. Oceanogr., 54, 347-360.

_ - N. L. Edmons, and C. W. Fan, 1999: Dynamical mechanisms for the South China Sea seasonal circulation and thermohaline variabilities. J. Phys. Oceanogr., 29, 2971-2989.

Dale, W. L., 1956: Winds and drift currents in the South China Sea. Malay J. Trop. Geogr., 8, 1-31.

Emery, K. O., and G. T. Csanady, 1973: Surface circulation of lakes and nearly land-locked seas. Proc. Natl. Acad. Sci. U.S.A., 70, 93-97.

Hu, Y., C. Guan, and H. Gao, 1992: Water temperature and circulation structure in the upper ocean of the northern South China Sea (in Chinese with English abstract). Oceanogr. China, 6, 60-69.

Huang, Q. Z., W. Z. Wang, Y. S. Li, and C. W. Li, 1994: Current characteristics of the South China Sea. Oceanology of China Seas, D. Zhou, Y. B. Liang, and C. K. Tseng, Eds., Kluwer Academic, 113-122.

Keffer, T., 1985: The ventilation of the world's oceans: Maps of the potential vorticity field. J. Phys. Oceanogr., 15, 509-523.

Li, L., W. D. Nowlin Jr., and J. Su, 1998: Anticyclonic rings from the Kuroshio in the South China Sea. Deep-Sea Res., 45, 14691482.

Li, R.-F., D.-J. Guo, and Q.-C. Zeng, 1996: Numerical simulation of interrelation between the Kurishio and the current of the northern South China Sea. Prog. Natural Sci., 6, 325-332.

McCartney, M. S., 1982: The subtropical recirculation of mode waters. J. Mar. Res. (Suppl.), 40, 427-464.

Metzger, E. J., and H. E. Hurlburt, 1996: Coupled dynamics of the 
South China Sea, the Sulu Sea, and the Pacific Ocean. J. Geophys. Res., 101, 12 331-12 352.

Nitani, H., 1970: Oceanographic conditions in the sea east of Philippines and Luzon Strait in summer of 1965 and 1966. The Kuroshio-A Symposium on Japan Current, J. D. Marr, Ed., East-West Press, 213-232.

Shaw, P.-T., 1989: The intrusion of water masses into the sea southwest of Taiwan. J. Geophys. Res., 94, 18 213-18 226.

— 1991: The seasonal variation of the intrusion of Philippine Sea water into the South China Sea. J. Geophys. Res., 96, 821-827.

- , and S.-Y. Chao, 1994: Surface circulation in the South China Sea. Deep-Sea Res., 41, 1663-1683.

Soong, Y. S., J. H. Hu, C. R. Ho, and P. P. Niiler, 1995: Cold-core eddy detected in South China Sea. Eos, Trans. Amer. Geophys. Union, 76, 345-347.

South China Sea Institute of Oceanology, 1985: Integrated investigation report on sea area of the South China Sea (in Chinese). Vol. 2, 311 pp. [Available from South China Sea Institute of Oceanology, 164 West Xingang Road, Guangzhou 510301, China.]
Stommel, H., and F. Schott, 1977: The beta spiral and the determination of the absolute velocity field from hydrographic station data. Deep-Sea Res., 24, 325-329.

Talley, L. D., 1988: Potential vorticity distribution in the North Pacific. J. Phys. Oceanogr., 18, 89-106.

Teague, W. J., M. J. Carron, and P. J. Hogan, 1990: A comparison between the Generalized Digital Environmental Model and Levitus climatologies. J. Geophys. Res., 95, 7167-7183.

Uda, M., and T. Nakao, 1972: Water masses and currents in the South China Sea and their seasonal changes. Third Cooperative Study of the Kuroshio and Adjacent Regions (CSK) Symp., Bangkok, Thailand, United Nations Educational, Scientific and Cultural Organization, 161-188.

Wunsch, C., 1978: The general circulation of the North Atlantic west of $50^{\circ} \mathrm{W}$ determined from inverse method. Rev. Geophys., 16, 583-620.

Wyrtki, K., 1961: Scientific results of marine investigations of the South China Sea and Gulf of Thailand 1959-1961. Naga Rep. 2, Scripps Institution of Oceanography, University of California, San Diego, 195 pp. [Available from Scripps Institution of Oceanography, La Jolla, CA 92093.] 